BNL-114564-2017-JA

\title{
Intermediate selectivity in the oxidation of phenols using plasmonic $\mathrm{Au} / \mathrm{ZnO}$ photocatalysts
}

\author{
F. Lin, H. L. Xin
}

Accepted by Nanoscale

June 2017

Center For Functional Nanomaterials

Brookhaven National Laboratory

\author{
U.S. Department of Energy \\ USDOE Office of Science (SC), \\ Basic Energy Sciences (BES) (SC-22)
}

Notice: This manuscript has been co-authored by employees of Brookhaven Science Associates, LLC under 


\section{DISCLAIMER}

This report was prepared as an account of work sponsored by an agency of the United States Government. Neither the United States Government nor any agency thereof, nor any of their employees, nor any of their contractors, subcontractors, or their employees, makes any warranty, express or implied, or assumes any legal liability or responsibility for the accuracy, completeness, or any third party's use or the results of such use of any information, apparatus, product, or process disclosed, or represents that its use would not infringe privately owned rights. Reference herein to any specific commercial product, process, or service by trade name, trademark, manufacturer, or otherwise, does not necessarily constitute or imply its endorsement, recommendation, or favoring by the United States Government or any agency thereof or its contractors or subcontractors. The views and opinions of authors expressed herein do not necessarily state or reflect those of the United States Government or any agency thereof. 


\section{Intermediate Selectivity in the Oxidation of Phenols using Plasmonic Au/ZnO Photocatalysts}

Received 00th January 20xx Accepted 00th January 20xx
Feng Lin, ${ }^{a, b,+}$ Bogdan E. Cojocaru, ${ }^{c,+}$ Luke S. Williams, ${ }^{a,}{ }^{+}$Christopher A. Cadigan, ${ }^{a}$ Chixia Tian, ${ }^{a}$ Maria N. Grecu, ${ }^{d}$ Huolin L. Xin, ${ }^{e}$ Shubham Vyas, ${ }^{a}$ Vasile I. Parvulescu, ${ }^{* c}$ and Ryan M. Richards*a

Tunable reaction selectivity on a single catalyst is a continual goal in chemical syntheses. Herein, we report an unexpected light-directed intermediate selectivity using well-known plasmonic photocatalysts (e.g., $\mathrm{Au} / \mathrm{ZnO}, \mathrm{Cu} / \mathrm{ZnO}, \mathrm{Ag} / \mathrm{ZnO}, \mathrm{Au} / \mathrm{TiO}_{2}$ ). We observed distinct intermediate selectivity behaviors between using UV and visible light irradiations. Chemical computations and quenching experiments suggest that the radicals generated by the plasmonic excitation govern the lightdirected selectivity. The broader impact of this work ranges from selective yield of desirable intermediates for subsequent syntheses without tedious separation procedures, to arousing interest in examining new opportunities for plasmonic photocatalysts.

\section{Introduction}

Obtaining selective yields among organic products is a continuous endeavor within the catalysis field. ${ }^{1}$ As global demands for greener, more efficient energy technologies continue to rise - in response to the long-term implications underpinning global warming and future energy demands - so, too, does the need for improved catalysts and a deeper understanding of their mechanisms. One promising direction within heterogeneous catalysis has been the advent of hybrid plasmonic nanoparticle/semiconductor catalysts, which have shown to have synergistic effects between the photo-induced surface plasmon resonance (SPR) of the nanoparticles and the charge carrying characteristics of the conduction band in semiconductor materials. While there is some understanding of the interaction between plasmonic metal nanoparticles and semiconductors, there remain significant questions in how these composite photocatalysts induce and propagate selectivity in chemical reactions. ${ }^{2}$

Plasmonic gold, copper and silver nanoparticles (nanoparticles that exhibit photo-induced SPR) represent one such class of efficient photocatalysts that utilize visible light to initiate electron excitation and enable photocatalytic processes, i.e., plasmonic photocatalysis. ${ }^{3-8}$ State-of-the-art plasmonic photocatalysts allow for superior reaction activities relative to conventional semiconductor photocatalysts (e.g., $\mathrm{ZnO}, \mathrm{TiO}_{2}$ ) under visible light irradiation. . 9,10 Plasmonic nanoparticles have been conjugated with a semiconductive material to achieve concerted effects between band-gap excitation and plasmonic excitation from the semiconductor and plasmonic nanoparticles, respectively. ${ }^{8,9}$ Significant efforts have been devoted to developing these materials with unique properties as well as to further elucidating the photocatalytic mechanism(s) to enable a better understanding of plasmonic photocatalysts.6,11-17 Tunable reaction selectivity on a single

a. Department of Chemistry, Colorado School of Mines, Golden, CO 80401, USA

b. Department of Chemistry, Virginia Tech, Blacksburg, VA 24061.

c. Department of Organic Chemistry, Biochemistry and Catalysis, University of Bucharest, Bucharest 030016, Romania.

d. National Institute of Materials Physics, Magurele-Ilfov 077125, Romania.

e. Center for Functional Nanomaterials, Brookhaven National Laboratory, Upton, NY 11973 , USA

+ These authors contributed equally to this work.

Electronic Supplementary Information (ESI) available: Further experimental details and characterizations, and computational details. See DOI: 10.1039/x0xx00000x catalyst is a long-sought goal in heterogeneous catalysis. ${ }^{18}$ To date, however, this topic remains largely unexplored for plasmonic photocatalysis, a thorough study of which would benefit many aspects of chemical catalysis.

Variable end product distributions have been demonstrated in recent studies with plasmonic photocatalysts. ${ }^{19,20}$ Tunable electron transfer and local electronic states diversify reaction active sites ${ }^{21,22}$ thereby potentially providing alternative routes for controlling catalytic conversion and selectivity on a single plasmonic photocatalyst. In addition, new metal-metal oxide interfacial phenomena of plasmonic photocatalysts (e.g., AuZnO interface) could modify the chemical bonding between reaction intermediates and catalytic active sites. These unexplored yet essential possibilities lead us to pursue lightdirected photocatalytic intermediate selectivity on plasmonic photocatalysts. Photocatalytic oxidation of phenol in aqueous solution was selected to study the light-directed intermediate selectivity and overall yield. Selective yield of the intermediate molecules from the phenol oxidation implies the site-specific attack of photoelectrons and free radicals on benzene rings, which is of significance to synthetic organic chemistry. ${ }^{23}$
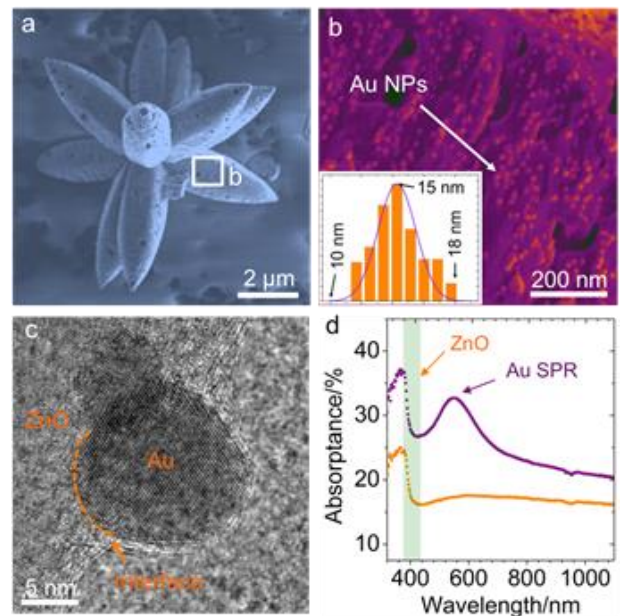

Many plasmonic photocatalysts have been reported to date, and we herein chose $\mathrm{Au} / \mathrm{ZnO}$ as a model system. Gold nanoparticles were dispersed onto flower-like $\mathrm{ZnO}$ and irradiated under both visible and UV light in the presence of phenol. Under visible light, this system showed both high selectivity and conversion for one phenol intermediate derivative, while no such distinction was observed for the system exposed to UV radiation nor when pristine $\mathrm{ZnO}$ (without 
the Au nanoparticles) was tested under the same conditions. This outcome suggests the role in which hybrid nanoparticlesemiconductor photocatalysts and SPR play in selective heterogeneous catalysis. Alongside experimental methods used to uncover the source of this selectivity, electronic structure calculations support the observed experimental phenomena.

\section{Methods}

\section{Experimental}

A structurally well-defined $\mathrm{ZnO}$ semiconductor ${ }^{24}$ was synthesized first by a pseudo-supercritical fluid drying method, followed by the deposition of Au nanoparticles on its surface to fabricate composite plasmonic photocatalysts (see SI for experimental details). SEM micrographs (Fig. 1a-b) show highly dispersed Au nanoparticles on $\mathrm{ZnO}$ with an average particle size of $15 \mathrm{~nm}$ (Inset of Fig. 1b). It is noted that the surface roughness of $\mathrm{ZnO}$ increased after Au deposition (Figs. S1 and S2). Au and $\mathrm{ZnO}$ are well interfaced as exemplified by the HRTEM image (Fig. 1c). EDS quantitative analysis shows that the atomic percentage of $\mathrm{Au}$ is $0.3 \pm 0.06 \%$ (Fig. S3). Furthermore, UV-Vis spectroscopy shows clear fingerprint absorption characteristics for both Au and $\mathrm{ZnO}$ (Fig. 1d). The optical band-gap value of $\mathrm{ZnO}$ remains unchanged after $\mathrm{Au}$ deposition, as indicated by the identical band-gap absorption edges at $\sim 400 \mathrm{~nm}$ (i.e., $3.1 \mathrm{eV}$ ). $\mathrm{Au}$ nanoparticles exhibit a wide surface plasmon resonance (SPR) peak centered at $\sim 550 \mathrm{~nm}$, which largely overlaps with the visible light source adopted in the present study (Fig. S4).

\section{Theoretical}

To support the experimental results, theoretical computations were conducted using hybrid density functional theory (DFT) ${ }^{25,26}$ through the Gaussian09 software package. ${ }^{27}$ The calculations were performed with the M06-2X density functional and combined with an augmented Pople splitvalence triple- $\zeta$ basis set of $6-311+G(2 d, 2 p) .{ }^{28}$ The M06-2X functional is solely parameterized for nonmetals and was developed to accommodate nonlocal exchange, making it highly effective for thermochemistry and kinetic calculations. ${ }^{29}$ The Integral Equation Formalism of the Polarizable Continuum Model (IEFPCM) ${ }^{30,31}$ was used in order to mimic the aqueous environment of the experiment. This implicit solvation method enforces a solvent dielectric around a cavity space in which the solute exists. The discussion of computational results can be found towards the end of this paper. (For information pertaining to thermodynamic and kinetic calculations, see SI).

Fig. 1 (a-b) SEM micrographs of Au/ZnO (inset shows Au size distribution), (c) HRTEM image of $\mathrm{Au} / \mathrm{ZnO}$ visualizing $\mathrm{Au}$ and $\mathrm{ZnO}$ interface (dashed line), and (d) UV-Vis-NIR spectra for $\mathrm{ZnO}$ and $\mathrm{Au} / \mathrm{ZnO}$.

\section{Results and discussion}

The major liquid-phase intermediates are shown in Scheme 1 and include catechol (P1), 1,2-benzoquinone (P2), resorcinol (P3), hydroquinone (P4), 1,4-benzoquinone (P5) and hydroxyquinone (P6). Note that formic acid and acetic acid were not detected likely due to their rapid conversion to $\mathrm{CO}_{2}$ and
$\mathrm{H}_{2} \mathrm{O}$. A combination of conversions and selectivities are reported for these intermediates over time. For clarity, 'conversion' is defined as the amount of each intermediate formed relative to the total starting material (phenol) while 'selectivity' is the amount of one intermediate formed compared to the total amount of intermediates at a given time. In this manner, a complete picture of the catalytic efficiency of each system can be gained.

The intermediate distribution after 3 hours of reaction is shown in Fig. $2 \mathrm{a}$ for the $\mathrm{Au} / \mathrm{ZnO}$ photocatalyst. Under UV irradiation, 1,2-benzoquinone (P2), hydroquinone (P4) and 1,4benzoquinone (P5) are the major intermediates, however a look at the overall catalytic activity shows relatively low yield for all four (Fig. S5c). In contrast, 1,4-benzoquinone (P5) is the sole dominant (93.3\%) intermediate when the reaction was performed under visible light irradiation and the highest yield for a single intermediate among the experimental systems at 76.9\% (Fig. S5d). No observable change of intermediate selectivity was found in the control experiment using pristine $\mathrm{ZnO}$ (Fig. 2b), or in the reaction using commercial $\mathrm{ZnO}$ (see Fig. S6). Note that the photoactivity of $\mathrm{ZnO}$ under visible light irradiation observed in this study likely originated from the defect states. ${ }^{32,33}$ The synthesized $\mathrm{ZnO}$ showed different catalytic behaviors compared to commercial $\mathrm{ZnO}$ likely due to the unique facet termination and surface defects. ${ }^{24}$ In addition, the visible light inactive $\mathrm{Pt} / \mathrm{ZnO}$ provides less significant selectivity change (Fig. 7Sa) and remarkably lower overall conversion (comparing Fig. S7b and Fig. S8). After 3 hours of reaction, the highest phenol conversion was found in the reaction catalyzed by $\mathrm{Au} / \mathrm{ZnO}$ under visible light irradiation
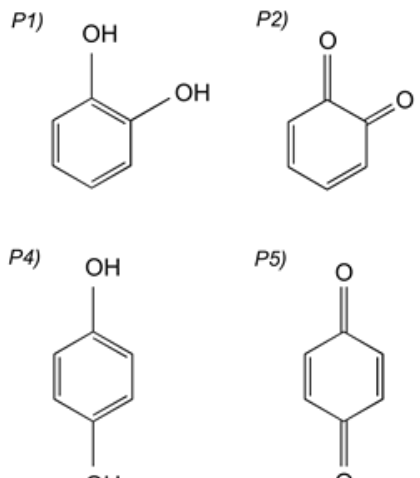

$\mathrm{OH}$

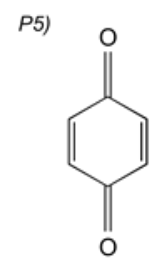

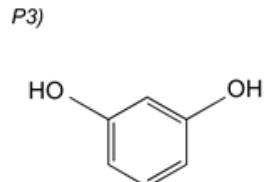

P6)

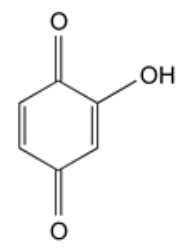

Scheme 1 Intermediate molecules identified during phenol oxidation: P1, P2, P3, P4, P5 and P6 represent catechol, 1,2-benzoquinone, resorcinol, hydroquinone, 1,4benzoquinone and hydroxyquinone, respectively.

(Fig. S8). Furthermore, the photocatalytic activity (i.e., conversion) of $\mathrm{Au} / \mathrm{ZnO}$ is better under visible light irradiation than that under UV irradiation (Fig. S8). Therefore, one can infer that the SPR of Au nanoparticles plays a major role in the photocatalytic process and influences the intermediate selectivity and overall conversion. Au4f XPS shows there is no major change in the Au oxidation state after the photocatalytic reaction (Fig. S9). Tunable selectivity in the present study is significantly distinct from the reported results in the literature, where the photocatalytic selectivity was predominantly tuned via alternative selection of photocatalysts. ${ }^{34-36}$ 
Next, we have investigated the time-dependent intermediate selectivity to probe the build-up process of 1,4benzoquinone (P5), as shown in Fig. 3. Under UV irradiation, the selectivity of $\mathrm{Au} / \mathrm{ZnO}$ towards 1,4-benzoquinone only showed a moderate increase (Fig. 3a), while the selectivity

was enhanced dramatically as a function of time when the reaction was performed under visible light irradiation (Fig. 3b). In addition, the number of intermediates becomes smaller as the reaction proceeded indicating that intermediateintermediate conversion most likely occurred during the course of the photocatalytic reaction. A look at the time-dependent evolution of each of the six intermediates concisely shows how interconversion assists in the selective yield of certain products (Fig. S10). Selective oxidation of the hydroxyl groups of catechol (P1) and hydroquinone (P4) necessarily lead to the formations of 1,2-benzoquinone (P2) and 1,4-benzoquinone (P5), respectively. Indeed, there is a noticeable inverse relationship between these two sets of intermediates when looking at their catalysis over pristine $\mathrm{ZnO}$ (Figs. S10a and S10b). This distinct inverse relationship becomes altered for $\mathrm{Au} / \mathrm{ZnO}$, showing a steady increase of both pairs of intermediates (P1/P2 and P4/P5) until hour 2 where the benzoquinone products become favored (Fig. S10), further suggesting a nontrivial change in the reaction mechanism when $\mathrm{Au}$ is present.

In the reactions catalyzed by pristine $\mathrm{ZnO}$ materials (Figs. 3c and $3 d$ ), several interesting phenomena were observed. First, significant selectivity towards hydroquinone (P4) occurs in the early stage ( 0.5 hour) of the reaction when switching from UV irradiation to visible light irradiation. However, the overall percentage of intermediates is only $0.2 \%$ at that point $(99.8 \%$ is still phenol, Fig. S11), which makes the selectivity less meaningful in practice. Second, resorcinol (P3) was a dominant molecular product in the reaction performed under both UV irradiation and visible irradiation, as long as the reaction was carried out long enough for the latter (e.g., 3 hours). Literature also reported the detection of resorcinol in the photo-oxidation of phenol on $\mathrm{ZnO}$ in spite of the fact its formation is less likely from the thermodynamic point of view. ${ }^{37}$ While selectivity towards resorcinol can be realized with pristine $\mathrm{ZnO}$ based on the choice of irradiation wavelengths, the elevated selectivity and moderate yield (54.4\%) only occurred when UV irradiation was applied, which is contrary to the reactions catalyzed by $\mathrm{Au} / \mathrm{ZnO}$. It is always desirable to perform photocatalytic reactions under visible light irradiation due to the vast availability of free visible light from the natural sunlight. Furthermore, the conversion and reaction rate are significantly enhanced with plasmonic photocatalysts (e.g., $\mathrm{Au} / \mathrm{ZnO}$ ) compared to regular semiconductive photocatalysts (e.g., $\mathrm{ZnO}$ ). Therefore, plasmonic photocatalysts are preferred for realizing visible light-directed catalytic intermediate selectivity.

Furthermore, chemisorption experiments conducted on catechol, hydroquinone and resorcinol (i.e. the three intermediates of the reaction) confirm these previous results. Catechol and hydroquinone are chemisorbed in a larger extent onto the $\mathrm{ZnO}$ catalyst, which may explain the easier oxidation of these molecules. The maximum quantity of chemisorbed resorcinol corresponds to a population of chemisorption sites of
$4.2 \times 10^{17} \mathrm{moles} / \mathrm{g}$, while for catechol and hydroquinone $1.7 \times$ $10^{19} \mathrm{moles} / \mathrm{g}$ and $1.8 \times 10^{19} \mathrm{moles} / \mathrm{g}$, respectively. For the $\mathrm{Au} / \mathrm{ZnO}$ photocatalyst, the order was inverse, i.e. $0.98 \times$ $10^{19} \mathrm{moles} / \mathrm{g}$ for resorcinol and $2.1 \times 10^{17} \mathrm{moles} / \mathrm{g}$ and $2.0 \times$ $10^{17} \mathrm{moles} / \mathrm{g}$ for catechol and hydroquinone, respectively.

We have also studied the impact of Au particle size and found that the conversion of phenol increased with the decrease of the Au particle size, and the highest conversion
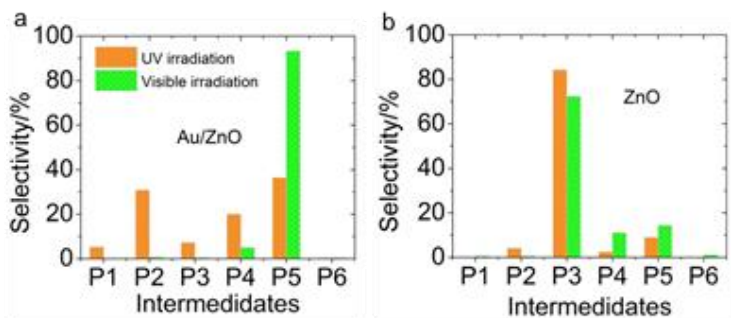

Figure 2. Intermediate selectivity at 3 hours of phenol oxidation catalyzed by (a) $\mathrm{Au} / \mathrm{ZnO}$ and (b) $\mathrm{ZnO}$.
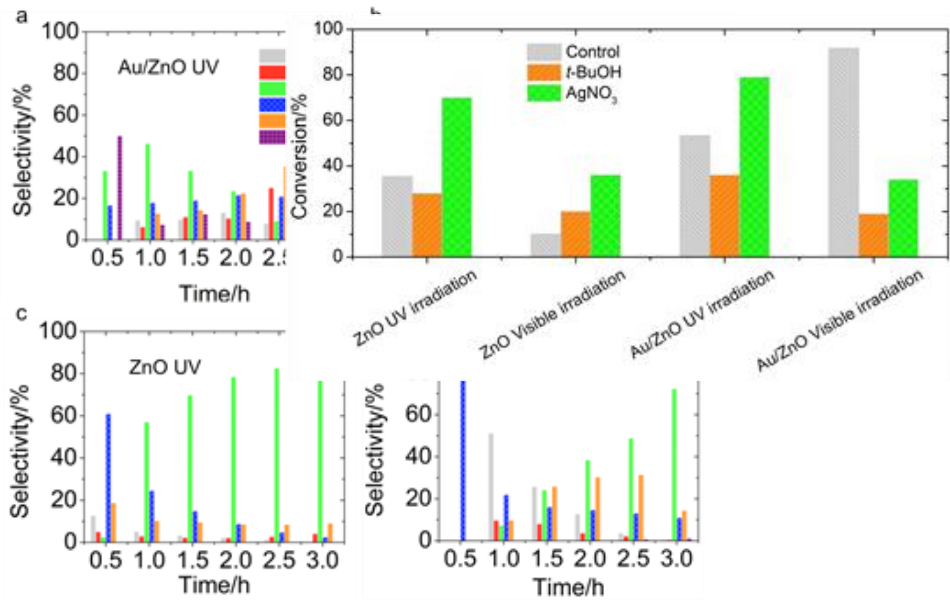

Figure 3. Time-dependent intermediate selectivity with (a) Au/ZnO under UV irradiation and (b) $\mathrm{Au} / \mathrm{ZnO}$ under visible light irradiation as compared to that of (c) $\mathrm{ZnO}$ under UV irradiation and (d) $\mathrm{ZnO}$ under visible light irradiation.

was reached for the catalyst with Au particle size of $15 \mathrm{~nm}$ (Table S1 and Fig. S8). The light-directed selectivity tuning is not limited to $\mathrm{Au} / \mathrm{ZnO}$ but is also found in other plasmonic photocatalysts, including $\mathrm{Au} / \mathrm{TiO}_{2}, \mathrm{Ag} / \mathrm{ZnO}$ and $\mathrm{Cu} / \mathrm{ZnO}$ (Fig. $\mathrm{S} 12)$. The selectivity of these materials towards 1,4benzoquinone is likely associated with the selective attack of hydroxyl free radicals at the para position and a ratedetermining step in the keto conversion to acids (i.e., formic acid, acetic acid). It is also worthwhile to mention that no major change in the $\mathrm{Ag}$ oxidation state was observed after the photocatalytic reaction, whereas the $\mathrm{Cu}$ oxidation state is unclear due to the similarity between $\mathrm{Cu}$ and $\mathrm{Cu}_{2} \mathrm{O}$ (Fig. S8). ${ }^{38}$

In order to probe the active species that initiate the photocatalytic reaction, tert-butyl alcohol $(t-\mathrm{BuOH}, 10 \mathrm{mmol} \cdot \mathrm{L}-$ $\left.{ }^{1}\right)$ and $\mathrm{AgNO}_{3}\left(6 \mathrm{mmol} \cdot \mathrm{L}^{-1}\right)$ were introduced as scavengers for 
hydroxyl radicals $\left({ }^{\circ} \mathrm{OH}\right)$ and electrons $\left(\mathrm{e}^{-}\right)$, respectively. ${ }^{39,40}$ There are a number of possible reaction pathways for the photocatalytic degradation of organic compounds. ${ }^{41}$ In the aqueous photocatalytic reaction, photo-generated holes $\left(h^{\bullet}\right)$ are scavenged by surface hydroxyl groups and generate strong oxidizing hydroxyl radicals, while dissolved oxygen molecules can scavenge the photoelectrons $\left(\mathrm{e}^{-}\right)$and generate $\mathrm{O}_{2}{ }^{--}$ radicals. These radicals exhibit strong oxidizing capabilities towards organic compounds in the aqueous solution. The inclusion of foreign scavengers results in competition for holes and electrons, and alters the reaction pathways, ultimately leading to changes in photocatalytic conversion and selectivity. As shown in Fig. 4, the overall conversion was significantly altered in the presence of scavengers. Under UV irradiation, $\mathrm{ZnO}$ and $\mathrm{Au} / \mathrm{ZnO}$ exhibit similar responses to the foreign scavengers, i.e., $t$ - $\mathrm{BuOH}$ decreases the conversion, while $\mathrm{AgNO}_{3}$ increases the conversion. These results suggest that the photocatalytic oxidation of phenol likely proceeds through a hydroxyl radical pathway under UV irradiation. $\mathrm{ZnO}$ and $\mathrm{Au} / \mathrm{ZnO}$ show distinct behaviors under visible irradiation: adding $t-\mathrm{BuOH}$ or $\mathrm{AgNO}_{3}$ increased the conversion in the reaction catalyzed by $\mathrm{ZnO}$ under visible irradiation, whereas

Figure 4. Effects of adding hydroxyl scavenger ( $t-\mathrm{BuOH}$, orange columns) and electron scavenger $\left(\mathrm{AgNO}_{3}\right.$, green columns) into the photocatalytic systems. The conversion rates were measured at the end of a 3-hour reaction period.

the conversion was significantly reduced when the scavengers were present in the $\mathrm{Au} / \mathrm{ZnO}$-catalyzed reaction under visible irradiation, which strongly implies that the plasmonic photocatalysis primarily involves the radical pathways (i.e., ${ }^{\bullet} \mathrm{OH}$, $\mathrm{O}_{2}^{\bullet-}$ ).

In the presence of foreign scavengers, the intermediate selectivity is no longer tunable by the irradiation light source. For example, the reactions yielded hydroquinone as the dominant intermediate in the presence of $\mathrm{AgNO}_{3}$ under both UV and visible irradiation using the plasmonic $\mathrm{Au} / \mathrm{ZnO}$ photocatalyst (Fig S13). These results suggest photo-induced radicals largely affect the light-directed intermediate selectivity in the $\mathrm{Au} / \mathrm{ZnO}$-catalyzed reaction. In situ electron paramagnetic resonance (EPR) measurements of phenol oxidation confirmed the role of plasmonic gold in activating oxygen under visible irradiation (Figs. S14-16).

Quantum chemical calculations were performed on various possible reaction pathways of phenol oxidation via hydroxyl radical without the presence of any catalysts (Fig. S17). Thus, these results are best considered as the fundamental conversion of phenol in the presence of hydroxyl radicals. As a result, deviations from these pathways as seen in the $\mathrm{ZnO}$ and $\mathrm{Au} / \mathrm{ZnO}$ experiments elucidate possible reaction mechanisms.

Each of the diols P1, P3, and P4 falls into a comparable thermodynamic well; these values being -117.4, -118.4, and $116.3 \mathrm{kcal} / \mathrm{mol}$ for catechol (P1), resorcinol (P3), and hydroquinone (P4), respectively. Activation barriers for their formation are $4.1,7.3$ and $4.5 \mathrm{kcal} / \mathrm{mol}$ resulting in rate constants of $6.33 \times 10^{9} \mathrm{M}^{-1} \mathrm{~s}^{-1}, 2.50 \times 10^{7} \mathrm{M}^{-1} \mathrm{~s}^{-1}$ and $3.04 \times 10^{9}$ $\mathrm{M}^{-1} \mathrm{~s}^{-1}$ for catechol, resorcinol and hydroquinone, respectively. These values are in agreement with previous computational results and support the fact that the radical resulting from hydroxyl radical attack at ortho and para positions will be stabilized by the existing alcohol group through resonance. ${ }^{42}$ According to these energetics, resorcinol formation should be the slowest. However, resorcinol was the major product after 3 hours of UV irradiation for ZnO which could possibly be attributed to selective phenol orientation on the $\mathrm{ZnO}$ surface, promoting formation of resorcinol in time. Based on the scavenger experiments, it is also thought that the hydroxyl radical addition is the primary pathway to the formation of the intermediates, implying that the SPR of $\mathrm{Au} / \mathrm{ZnO}$ under visible light irradiation generates an abundant amount of free radical species in solution thus altering the reaction pathway. Moreover, a competition between plasmon-induced photochemical reaction and degradation pathways was observed for plasmonic catalysts ${ }^{43}$ which can explain the formation of different reaction intermediates.

The selectivity and yield of intermediate P5, whose precursor is $\mathrm{P} 4$, was the highest of all under the in the presence of the Au/ZnO irradiated by visible light. However, the activation barrier for the free hydroxyl attack on ortho and para position of phenol shows a negligible difference (vide infra). This further suggests that phenol orientation on the $\mathrm{Au} / \mathrm{ZnO}$ photocatalytic surface preferentially aligns itself such that the radical attack of the para position is highly favored. Furthermore, formation of P5 from P4 is thermodynamically more favorable $(\Delta H=-92.7 \mathrm{kcal} / \mathrm{mol})$ than formation of $\mathrm{P} 2$ from $\mathrm{P} 1(\Delta H=-86.1 \mathrm{kcal} / \mathrm{mol})$. The oxidation of hydroquinone (P4) to 1,4 -benzoquinone (P5) is associated with an enthalpy of -92.7 $\mathrm{kcal} / \mathrm{mol}$. Product P6 was never observed in high quantities in any of the systems, although calculated thermodynamics suggest that its formation is highly favorable from P1, P3 and P4. This would imply that the activation barriers for the intermediate steps are significantly high and even over longer periods it would by hypothesized that P6 would not be a significant intermediate.

\section{Conclusions}

In summary, light-directed catalytic selectivity is reported on a single photocatalyst. Plasmonic Au/ZnO shows not only much improved photocatalytic activity (both under UV and visible irradiations) but also superior light-directed intermediate selectivity. Chemical computations showed that orientation of phenol over the catalyst plays a key role in the observed photoselectivity. The mechanistic investigation suggests that the radical pathway is a determinant factor for the selectivity, and $\mathrm{Au}$ is responsible for the oxygen activation under visible light irradiation. Interfacing plasmonic Au nanoparticles with semiconductive materials provides an alternative pathway to generate radicals and leads to the selectivity enhancement. We believe that a future study that focuses on the generation of free radicals as a function of visible light irradiation could provide insight into the exact role of plasmonic effect (e.g., local electrical field, temperature) in phenol oxidation. Finally, this work suggests that vast opportunities indeed exist in plasmonic photocatalysts for preferential generation of desirable intermediates in heterogeneous catalysis. 


\section{Acknowledgements}

F.L. gratefully acknowledges Virginia Tech Department of Chemistry startup funds. R. M. R. acknowledges support from NSF Chemical Catalysis program 1214068. S/TEM experiments were performed at the Center for Functional Nanomaterials, Brookhaven National Laboratory, which is supported by the U.S. Department of Energy, Office of Basic Energy Sciences under Contract No. DE-AC02-98CH10886.

\section{Notes and references}

1 G. A. Somorjai, and C. J. Kliewer, React. Kinet. Catal. Lett., 2009, 96, 191.

2 S. M. Kim, S.W. Lee, S. Y. Moon, and J. Y. Park, J. Phys.: Condens Matter, 2016, 28, 254002.

3 P. Wang, B. Huang, X. Qin, X. Zhang, Y. Dai, J. Wei, and M.-H. Whangbo, Angew. Chem. Int. Ed., 2008, 47, 7931.

4 L. Liu, S. Ouyang, and J. Ye, Angew. Chem. Int. Ed., 2013, 6689

5 A. Marimuthu, J. Zhang, and S. Linic, Science, 2013, 339, 1590.

6 S. Linic, P. Christopher, and D. B. Ingram, Nat. Mater., 2011 10, 911.

7 F. Meng, S. K. Cushing, J. Li, S. Hao, and N. Wu, ACS Catal., 2015, 5, 1949.

8 T. Bora, D. Zoepfl, and J. Dutta, Nat. Sci. Rep., 2016, 6, 26913.

9 D. B. Ingram, and S. Linic, J. Am. Chem. Soc., 2011, 133, 5202

10 Q. Zhang, D. Q. Lima, I. Lee, F. Zaera, M. Chi, and Y. Yin, Angew. Chem. Int. Ed., 2011, 50, 7088.

11 P. Wang, B. Huang, Y. Dai, and M.-H. Whangbo, Phys. Chem. Chem. Phys., 2012, 14, 9813.

12 V. Subramanian, E. E. Wolf, and P. V. Kamat, J. Am. Chem. Soc., 2004, 126, 4943.

13 Y. Tang, Z. Jiang, G. Xing, A. Li, P. D. Kanhere, Y. Zhang, T. C. Sum, S. Li, X. Chen, Z. Dong, and Z. Chen, Adv. Funct. Mater., 2013, 23, 2932.

14 Ş. Neaţu, B. Cojocaru, V. I. Pârvulescu, V. Şomoghi, M. Alvaro, and H. Garcia, J. Mater. Chem., 2010, 20, 4050.

15 C. Hu, T. Peng, X. Hu, Y. Nie, X. Zhou, J. Qu, and H. He, J. Am. Chem. Soc., 2010, 132, 857.

16 X. Chen, H.-Y. Zhu, J.-C. Zhao, Z.-F. Zheng, and X.-P. Gao, Angew. Chem. Int. Ed., 2008, 47, 5353.

17 J. R. Adleman, D. A. Boyd, D. G. Goodwin, and D. Psaltis, Nano Lett., 2009, 9, 4417.

18 G. A. Somorjai, and J. Y. Park, Angew. Chem. Int. Ed. Engl., 2008, 47, 9212.

19 H. Zhu, X. Ke, X. Yang, S. Sarina, and H. Liu, Angew. Chem. Int. Ed., 2010, 49, 9657.

20 X. Ke, S. Sarina, J. Zhao, X. Zhang, J. Chang, and H. Zhu, Chem. Comm., 2012, 48, 3509.

21 A. F. Lee, C. V. Ellis, J. N. Naughton, M. A. Newton, C. M. A. Parlett, and K. Wilson, 2011, 5724.

22 A. Pestryakov, and V. Lunin, J. Mol. Catal. A Chem., 2000, 158, 325.

23 M. Bellardita, V. Augugliaro, V. Loddo, B. Megna, G. Palmisano, L. Palmisano, and M. A. Puma, Appl. Catal. A Gen., 2012, 441-442, 79.

24 L. Chen, J. Hu, F. Lin, C. Cadigan, W. Cao, Z. Qi, M. Pozuelo, S. V. Prikhodko, S. Kodambaka, and R. M. Richards, CrystEngComm, 2013, 15, 3780.

25 W. Kohn, and L. Sham, J. Phys. Rev., 1965, 140, A1133.

26 J. P. Perdew, J. A. Chevary, S. H. Vosko, K. A. Jackson, M. R. Pederson, D. J. Singh, and C. Fiolhais, Phys. Rev. B., 1992, 46, 6671.

27 Gaussian 09, Revision E.01, M. J. Frisch, G. W. Trucks, H. B. Schlegel, G. E. Scuseria, M. A. Robb, J. R. Cheeseman, G. Scalmani, V. Barone, B. Mennucci, G. A. Petersson, H.
Nakatsuji, M. Caricato, X. Li, H. P. Hratchian, A. F. Izmaylov, J. Bloino, G. Zheng, J. L. Sonnenberg, M. Hada, M. Ehara, K. Toyota, R. Fukuda, J. Hasegawa, M. Ishida, T. Nakajima, Y. Honda, O. Kitao, H. Nakai, T. Vreven, J. A. Montgomery Jr., J. E. Peralta, F. Ogliaro, M. Bearpark, J. J. Heyd, E. Brothers, K. N. Kudin, V. N. Staroverov, R. Kobayashi, J. Normand, K. Raghavachari, A. Rendell, J. C. Burant, S. S. Iyengar, J. Tomasi, M. Cossi, N. Rega, J. M. Millam, M. Klene, J. E. Knox, J. B. Cross, V. Bakken, C. Adamo, J. Jaramillo, R. Gomperts, R. E. Stratmann, O. Yazyev, A. J. Austin, R. Cammi, C. Pomelli, J. W. Ochterski, R. L. Martin, K. Morokuma, V. G. Zakrzewski, G. A. Voth, P. Salvador, J. J. Dannenberg, S. Dapprich, A. D. Daniels, Ö. Farkas, J. B. Foresman, J. V. Ortiz, J. Cioslowski, and D. J. Fox, Gaussian, Inc., Wallingford CT, 2009.

28 R. Krishnan, J. S. Binkley, R. Seeger, and J. A. Pople, J. Chem. Phys., 1980, 72, 650.

29 Y. Zhao and D. G. Truhlar, Theor. Chem. Account., 2008, 120, 215.

30 S. Miertuš, E. Scrocco, and J. Tomasi, Chem. Phys., 1981, 55 117.

31 M. Cossi, G. Scalmani, N. Rega, and V. Barone, J. Chem. Phys. 2002, 117, 43

32 S. Baruah, S. S. Sinha, B. Ghosh, S. K. Pai, A. K. Raychaudhuri, and J. Dutta, J. Appl. Phys., 2009, 105, 074308.

33 J. Wang, Z. Wang, B. Huang, Y. Ma, Y. Liu, X. Qin, X. Zhang, and Y. Dai, ACS Appl. Mater. Interfaces, 2012, 4, 4024.

34 S. Liu, J. Yu, and M. Jaroniec, J. Am. Chem. Soc., 2010, 132 11914.

35 S. Furukawa, T. Shishido, K. Teramura, and T. Tanaka, ACS Catal., 2012, 2, 175.

36 L. Baia, A. Vulpoi, T. Radu, É. Karácsonyi, A. Dombi, K. Hernádi, V. Danciu, S. Simon, K. Norén, S. E. Canton, G. Kovács, and Z. Pap, Appl. Catal. B Environ., 2014, 148-149, 589.

37 J. Al-Sabahi, T. Bora, M. Al-Abri, and J. Dutta, Materials, 2016 9, 238.

38 N. Pauly, S. Tougaard, and F. Yubero, Surf. Sci., 2014, 620, 17.

39 C. Zhao, M. Pelaez, X. Duan, H. Deng, K. O’Shea, D. FattaKassinos, and D. D. Dionysiou, Appl. Catal. B Environ., 2013 $134,83$.

40 Y. Huo, J. Zhang, M. Miao, and Y. Jin, Appl. Catal. B Environ. 2012, 111, 334

41 M. Y. Guo, A. M. C. Ng, F. Liu, A. B. Djurišić, and W. K. Chan Appl. Catal. B Environ., 2011, 107, 150.

42 M. Kılıç, G. Koçtürk, N. San, and Z. Çınar, Chemosphere, 2007 69, 1396.

43 J. L. Brooks and R. R. Frontiera, J. Phys. Chem. C, 2016, 120 20869.

44 W. M. K. P. Wijekoon, Z. Z. Ho, and W. M. Hetherington, J. Chem. Soc., Faraday Trans., 1993, 87, 1067. 